\title{
РАЗРАБОТКА СОДЕРЖАНИЯ ПРОГРАММЫ УЧЕБНОГО ПРЕДМЕТА «ФИЗИКА» ДЛЯ УЧАЩИХСЯ ПРОФИЛЬНОГО 7 КЛАССА, ОСНОВАНОГО НА ПРИНЦИПЕ МЕТАПРЕДМЕТНОСТИ
}

\section{Снигирева Людмила Николаевна}

магистр

МКОУ «Лицей № 7 имени Шуры Козуб с. Новоивановского»

Аннотация: в данной статье рассматривается пояснительная записка, в которой формулируются цели изучения физики на уровне основного общего образования, содержание программы учебного предмета «Физика» для учащихся 7 профильного класса, включающие перечень основного изучаемого материала и вариативных компонентов, распределённых по содержательным разделам, основанного на принципе метапредметности.

Ключевые слова: метапредметность, познавательные УУД, физики, методики, содержание.

\section{DEVELOPMENT OF THE CONTENT OF THE PROGRAM OF THE EDUCATIONAL SUBJECT "PHYSICS" FOR STUDENTS OF THE PROFILE 7TH GRADE, BASED ON THE PRINCIPLE OF METASUBJECT}

\section{Snigireva Lyudmila Nikolaevna}

\begin{abstract}
: this article discusses an explanatory note, which formulates the goals of studying physics at the level of basic general education, the content of the curriculum of the subject "Physics" for students of the 7th profile class, including a list of the main studied material and variable components distributed by content sections, based on the principle of meta-subject.
\end{abstract}

Key words: metasubject, cognitive UUD, physics, methods, content. 


\section{Пояснительная записка}

Содержание программы учебного предмета «Физика» для учащихся 7 профильного класса составлена в соответствии с требованиями федерального государственного стандарта оновного общего образования (далее ФГОС ООО) по физике, Основной образовательной программы МКОУ «Лицей № 7 имени Шуры Козуб с. Новоивановского», на основе авторской программы основного общего образования «Физика 7-9 классы» А.В. Пёрышкин, Н.В. Филонович, Е.М. Гутник. М.: Дрофа, 2020 г. и обеспечивает изучение предмета на углублённом уровне. Программа модифицирована по содержанию и количеству часов.

Содержание программы ориентирована на использование учебно-методического комплекса А.В. Пёрышкина. Физика. 7-9 классы. М.: «Дрофа» и авторской методики формирования познавательных универсальных учебных действий [5], основанной на научных исследованиях Краевского В.В., Хуторского А.В. [7], методики формирования познавательных УУД в работах Л.И. Боженковой [1], внедрение «новых методик» в преподавании физики Ивашкиной Д.А. [3]. Исходя из цели функционирования военного профиля школы, программа направлена на углублённое изучение курса физики в 7 классе, на выявление на ранних уровнях изучения способностей учащихся по тем или иным видам деятельности и их развития.

Цели изучения физики на уровне основного общего образования определены в Концепции преподавания учебного предмета «Физика» в образовательных организациях Российской Федерации, реализующих основные общеобразовательные программы, утверждённой решением Коллегии Министерства просвещения Российской Федерации, протокол от 3 декабря 2019 г. № ПК-4вн.

Цели изучения физики:

- приобретение интереса и стремления обучающихся к научному изучению природы, развитие их интеллектуальных и творческих способностей;

- развитие представлений о научном методе познания и формирование исследовательского отношения к окружающим явлениям;

- формирование научного мировоззрения как результата изучения основ строения материи и фундаментальных законов физики; 
- формирование представлений о роли физики для развития других естественных наук, техники и технологий;

- развитие представлений о возможных сферах будущей профессиональной деятельности, связанной с физикой, подготовка к дальнейшему обучению в этом направлении.

Достижение этих целей на уровне основного общего образования обеспечивается решением следующих задач:

- приобретение знаний о дискретном строении вещества, о механических явлениях;

- приобретение умений описывать и объяснять физические явления с использованием полученных знаний;

- освоение методов решения простейших расчётных задач с использованием физических моделей, творческих и практико-ориентированных задач;

- развитие умений наблюдать природные явления и выполнять опыты, лабораторные работы и экспериментальные исследования с использованием измерительных приборов;

— освоение приёмов работы с информацией физического содержания, включая информацию о современных достижениях физики; анализ и критическое оценивание информации;

- знакомство со сферами профессиональной деятельности, связанными с физикой, и современными технологиями, основанными на достижениях физической науки.

Углублённый уровень способствует получению образования, в соответствии с интересами, склонностями и способностями обучающихся, с их профессиональными интересами и намерениями в отношении продолжения образования. Изучение физики на углублённом уровне ставить своей целью завершение формирование у обучающихся целостной системы физических знаний как основы для продолжения образования в областях, связанных с физикой.

Направления развития образования XXI в. определяется запросами общества, движением к информационному обществу, а также внешними факторами: экономическими, социальными, культурными, цифровыми, демографическими, экологическими и даже эпидемиологическими. Внешние факторы определяют внутренние изменения в российском обществе, в частности, модернизацию российского образования (изменение заданий ЕГЭ, 
реализация приоритетного проекта «Образование», национальной образовательной инициативы «Наша новая школа», создание и функционированию в общеобразовательных организациях, расположенных в сельской местности и малых городах, центров образования естественно-научной и технологической направленностей («Точка роста»), международное иссследование функциональной грамотности PISA), обусловленную требованием информационного общества [2], [4], [6]. Исследования PISA, оценивают функциональную грамотность - способность человека определять и понимать роль науки в мире, в котором он живет, высказывать хорошо обоснованные научные суждения и использовать полученные знания так, чтобы удовлетворять в настоящем и будущем потребности, присущие созидательному, заинтересованному и мыслящему гражданину. Важность этого момента была осознана, в частности, авторами ФГОС, которые наряду с предметными результатами обучения включили также личностные и метапредметные результаты - универсальные учебные действия (УУД): познавательные, коммуникативные, регулятивные.

Особое значение это имеет и для естественно-математического образования, в том числе физического. Так, внедрение метапредметного подхода в школьное образование является острой необходимостью, т.к. традиционные средства и методы педагогической деятельности не соответствуют современным реалиям, уровню развития технического прогресса.

А.В. Хуторской отмечает, метапредметный подход - организация деятельности учащихся с целью передачи им способов работы со знанием [8].

Используя такой подход, школа способна сформировать у ребёнка представление о дисциплине, как о системе знаний о мире, выраженном в числах (математика), телах (физика), веществах (химия) и т.д. Здесь важна ориентация на результат обучения, и в качестве такового результата понимается, во-первых, способность применить полученные знания и умения, а во-вторых, мотивированность получения этих знаний и умений.

Изучение предмета «Физика» в части формирования у обучающихся научного мировоззрения, освоения общенаучных методов (наблюдение, измерение, эксперимент, моделирование), освоения практического применения научных знаний физики в жизни основано на межпредметных связях с дисциплинами «Математика», «Информатика», «Химия», «Биология», «География», «Экология», «Основы безопасности жизнедеятельности», «История», «Литература» и др. Это даёт возможность согласовать темы «Мини-проектов», что обусловлено содержанием наук и 
дидактическими целями. Проектные технологии в этом случае могут использоваться непосредственно на уроке физики в виде краткосрочных проектов, направленных на обучение школьников методом исследовательской деятельности, открытие новых фактов, установление взаимосвязи между дисциплинами [5].

Физика - экспериментальная наука, изучающая природные явления опытным путём. Концепция современного образования подразумевает, что в учебном эксперименте ведущую роль должен занять самостоятельный исследовательский ученический эксперимент. В Федеральном государственном образовательном стандарте (далее - ФГОС) прописано, что одним из универсальных учебных действий (далее - УУД), приобретаемых учащимися, должно стать умение «проведения опытов, простых экспериментальных исследований, прямых и косвенных измерений с использованием аналоговых и цифровых измерительных приборов» [6].

В основу курса физики положены как традиционные принципы построения учебного содержания (принципы научности, доступности, системности), так и идея, получившая свое развитие в связи с внедрением новых образовательных стандартов, - принцип метапредметности. Метапредметность как способ формирования системного мышления обеспечивает формирование целостной картины мира в сознании школьника.

Метапредметность - принцип интеграции содержания образования, развивающий принципы генерализации и гуманитаризации. Принцип метапредметности позволяет (на уровне вопросов, заданий после параграфа) в содержании физики выделять физические понятия, явления, процессы в качестве объектов для дальнейшего исследования в межпредметных и надпредметных (социальной практике) областях (метапонятия, метаявления, метапроцессы). Проектирование исследования учащегося на метапредметном уровне опирается как на его личные интересы, склонности к изучению физики, так и на общекультурный потенциал физической науки.

В рабочую программу внесены изменения: добавлены часы на выполнение исследований и наблюдений с использованием цифровых технологий, тем по решению задач повышенной сложности, творческих и экспериментальных задач, типовых заданий физического содержания, целью которых является развитие математического и логического мышления, расширение кругозора учащихся. Программа предусматривает более широкое использование математических знаний учащихся, знакомство с индуктивным методом установления основных законов природы на основе эксперимента и дедуктивного пути получения следствий из фундаментальных теоретических 
положений. Количество предлагаемых программой лабораторных опытов отвечает имеющемуся в кабинетах физики лабораторному оборудованию. Предусматривается обязательное выполнение учащимися фронтальных лабораторных работ. Темы углубленного курса физики распределены таким образом, что просматривается определенная последовательность, которая позволяет учащимся подготовиться к изучению курса физики в старшей школе.

Применение педагогами школы современных образовательных технологий позволяет проводить разнообразные по форме и содержанию уроки, что способствует повышению качества знаний учащихся, росту мотивации к учению, обеспечению индивидуальных запросов учащихся и родителей, отсутствию отрицательной динамики состояния здоровья. (Таблица 1).

Таблица 1

Классификация уроков по цели организации занятий

\begin{tabular}{|c|c|c|c|}
\hline \multirow{2}{*}{ Типы уроков } & \multirow{2}{*}{ Виды уроков } & \multicolumn{2}{|c|}{ Цель урока } \\
\hline & & Образовательная & Метапредметная \\
\hline $\begin{array}{c}\text { 1.Урок изучения } \\
\text { нового учебного } \\
\text { материала }\end{array}$ & $\begin{array}{c}\text { 1) урок-лекция } \\
\text { 2) урок-беседа } \\
\text { 3)урок выполнения } \\
\text { практических } \\
\text { работ(поискового типа) } \\
\text { 4)урок выполнения } \\
\text { теоретических } \\
\text { исследований } \\
\text { 5) смешанный урок } \\
\text { (сочетание различных } \\
\text { видов урока на одном } \\
\text { уроке) }\end{array}$ & $\begin{array}{c}\text { Изучение и первичное } \\
\text { закрепление новых } \\
\text { знаний, расширение } \\
\text { понятийной базы } \\
\text { учебной дисциплины }\end{array}$ & $\begin{array}{c}\text { Формирование у учащихся } \\
\text { способностей к } \\
\text { самостоятельному } \\
\text { построению новых } \\
\text { способов ПУД. }\end{array}$ \\
\hline $\begin{array}{c}\text { 2. Урок } \\
\text { комплексного } \\
\text { применения знаний } \\
\text { и умений } \\
\text { (закрепления } \\
\text { знаний) }\end{array}$ & $\begin{array}{l}\text { 1) урок решения задач } \\
\text { 2) урок выполнения } \\
\text { самостоятельных работ } \\
\text { (репродуктивного типа - } \\
\text { устных или письменных } \\
\text { упражнений) } \\
\text { 3) урок- } \\
\text { лабораторная работа } \\
\text { 4) урок-экскурсия } \\
\text { 5) семинар } \\
\text { 6) собеседование } \\
\text { 7) консультация }\end{array}$ & $\begin{array}{l}\text { Выработка умений по } \\
\text { применению знаний }\end{array}$ & $\begin{array}{c}\text { Формирование у учащихся } \\
\text { способностей к } \\
\text { самостоятельному } \\
\text { выявлению и исправлению } \\
\text { своих ошибок }\end{array}$ \\
\hline $\begin{array}{c}\text { 3. Урок } \\
\text { комплексного } \\
\text { применения знаний }\end{array}$ & $\begin{array}{l}\text { Сюда входят основные } \\
\text { виды всех пяти уроков }\end{array}$ & $\begin{array}{c}\text { Выработка умений } \\
\text { самостоятельно } \\
\text { применять знания в } \\
\text { комплексе, в новых } \\
\text { условиях }\end{array}$ & $\begin{array}{c}\text { Формирование } \\
\text { способностей выбора } \\
\text { способов ПУД в конкретной } \\
\text { ситуации и их } \\
\text { корректировки }\end{array}$ \\
\hline $\begin{array}{c}\text { 4. Урок обобщения } \\
\text { и систематизации } \\
\text { знаний } \\
\text { (Комбинированный } \\
\text { урок) }\end{array}$ & $\begin{array}{c}\text { Семинар } \\
\text { Конференции } \\
\text { Круглый стол } \\
\text { Дискуссия } \\
\text { Видеоурок }\end{array}$ & $\begin{array}{c}\text { Обобщение единичных } \\
\text { знаний в систему }\end{array}$ & $\begin{array}{c}\text { Формирование у учащихся } \\
\text { способностей к обобщению, } \\
\text { структурированию и } \\
\text { систематизации } \\
\text { предметного содержания } \\
\text { изучаемой дисциплины }\end{array}$ \\
\hline
\end{tabular}




\begin{tabular}{|c|c|c|c|}
\hline $\begin{array}{c}\text { 5. Урок } \\
\text { творческого } \\
\text { поиска }\end{array}$ & $\begin{array}{c}\text { 1) Урок одной задачи } \\
\text { 2) лабораторный } \\
\text { практикум } \\
\text { 3) Мини-проект } \\
\text { 4) Урок-игра } \\
\text { 5) межпредметные и } \\
\text { метапредметные } \\
\text { задания, } \\
\text { метапредметный урок } \\
\text { (предметный урок и } \\
\text { метапредметная тема), } \\
\text { межпредметный и } \\
\text { метапредметный } \\
\text { проекты }\end{array}$ & $\begin{array}{c}\text { Выработка умений } \\
\text { самостоятельно решать } \\
\text { задачи в проблемных } \\
\text { ситуациях (Ситуации } \\
\text { успеха) }\end{array}$ & $\begin{array}{c}\text { Формирования у учащихся } \\
\text { навыков выделения } \\
\text { проблемы, поиска способов } \\
\text { её решения, добычи } \\
\text { информации; доступ к } \\
\text { школьной электронной } \\
\text { библиотеке и т.п.), её } \\
\text { обобщения, представление } \\
\text { выводов в виде некоторого } \\
\text { конечного продукта. }\end{array}$ \\
\hline $\begin{array}{c}\text { 6. Урок } \\
\text { диагностики и } \\
\text { коррекции знаний } \\
\text { и умений } \\
\text { (диагностико- } \\
\text { коррекционный } \\
\text { урок) }\end{array}$ & $\begin{array}{c}\text { 1. Карты коррекции } \\
\text { (уровневый подход) } \\
\text { 2. Решение } \\
\text { демонстрационного } \\
\text { варианта контрольной } \\
\text { работы } \\
\text { 3. Составление } \\
\text { кроссворда } \\
\end{array}$ & $\begin{array}{c}\text { Выработка умений } \\
\text { анализировать и } \\
\text { исправлять свои ошибки }\end{array}$ & $\begin{array}{c}\text { Формирование у учащихся } \\
\text { способностей к } \\
\text { осуществлению рефлексии } \\
\text { и самоконтролю над } \\
\text { ошибками ввиду } \\
\text { достижения необходимых } \\
\text { результатов ПУд }\end{array}$ \\
\hline $\begin{array}{l}\text { 7. Урок контроля, } \\
\text { оценки и } \\
\text { коррекции знаний }\end{array}$ & $\begin{array}{c}\text { 1) устный опрос } \\
\text { (фронтальный, } \\
\text { индивидуальный, } \\
\text { групповой) } \\
\text { 2) письменный опрос } \\
\text { (индивидуальный) } \\
\text { 3) зачёт } \\
\text { 4) зачётная практическая } \\
\text { (лабораторная работа) } \\
\text { 5) контрольная работа } \\
\text { 6) коллоквиум } \\
\text { 7) смотр знаний (защита } \\
\text { проекта, презентации) } \\
\text { 8) смешанный урок }\end{array}$ & $\begin{array}{c}\text { Контроль и } \\
\text { самоконтроль уровня } \\
\text { усвоения изучаемых } \\
\text { понятий и способов } \\
\text { деятельности }\end{array}$ & $\begin{array}{c}\text { Формирование у учащихся } \\
\text { способностей к } \\
\text { осуществлению } \\
\text { контрольной функции }\end{array}$ \\
\hline
\end{tabular}

Метапредметные результаты обучения физике в основной школе включают межпредметные понятия и универсальные учебные действия (регулятивные, познавательные, коммуникативные).

Межпредметные понятия. Условием формирования межпредметных понятий, таких, как система, факт, закономерность, феномен, анализ, синтез является овладение обучающимися основами читательской компетенции, приобретение навыков работы $\mathrm{c}$ информацией, участие в проектной деятельности. В основной школе продолжается работа по формированию и развитию основ читательской компетенции. Обучающиеся овладеют чтением как средством осуществления своих дальнейших планов: продолжения образования и самообразования, осознанного планирования своего актуального и перспективного круга чтения, в том числе досугового, подготовки к трудовой и социальной деятельности. У выпускников будет 
сформирована потребность в систематическом чтении как средстве познания мира и себя в этом мире, гармонизации отношений человека и общества, создании образа «потребного будущего». При изучении физики обучающиеся усовершенствуют приобретенные навыки работы с информацией и пополнят их. Они смогут работать с текстами, преобразовывать и интерпретировать содержащуюся в них информацию, в том числе:

- систематизировать, сопоставлять, анализировать, обобщать и интерпретировать информацию, содержащуюся в готовых информационных объектах;

- выделять главную и избыточную информацию, выполнять смысловое свертывание выделенных фактов, мыслей;

- представлять информацию в сжатой словесной форме (в виде плана или тезисов) и в наглядно-символической форме (в виде таблиц, графических схем и диаграмм, карт понятий - концептуальных диаграмм, опорных конспектов);

- заполнять и дополнять таблицы, схемы, диаграммы, тексты.

В ходе изучения физики обучающиеся приобретут опыт проектной деятельности как особой формы учебной работы, способствующей воспитанию самостоятельности, инициативности, ответственности, повышению мотивации и эффективности учебной деятельности; в ходе реализации исходного замысла на практическом уровне овладеют умением выбирать адекватные стоящей задаче средства, принимать решения, в том числе и в ситуациях неопределенности. Они получат возможность развить способность к разработке нескольких вариантов решений, к поиску нестандартных решений, поиску и осуществлению наиболее приемлемого решения.

\section{СОДЕРЖАНИЕ УЧЕБНОГО КУРСА «ФИЗИКА»}

7 класс (102 часа, 3 часа в неделю)

В рабочую программу включен раздел «Практикум» (2 ч.) Введение (5 ч.) Физика - наука о природе. Физические явления. Физические свойства тел. Наблюдение и описание физических явлений. Физические величины. Измерения физических величин: длины, времени, температуры. Физические приборы. Международная система единиц. Точность и погрешность измерений. Абсолютная и относительная погрешность. Физика и техника. Современные достижения науки. Роль физики и ученых нашей страны в 
развитии технического прогресса. Влияние технологических процессов на окружающую среду. Абсолютная и относительная погрешность измерений.

Учебные понятия. Природа, физика, физическое явление, закономерность, физическое тело, физическая величина, вещество, взаимодействие, геоцентрическая и гелиоцентрическая системы мира, наблюдение, физический опыт, гипотеза, моделирование, прямое измерение, шкала физического прибора, единица измерения физической величины, погрешность, инструментальная погрешность.

Персоналии. М.В. Ломоносов, Н. Коперник, К. Птолемей, С.И. Вавилов, Г. Галилей.

Демонстрации. Физические приборы.

Основные образовательные идеи. Точность измерений. Сравнение цены деления двух одинаковых измерительных приборов (линейки).

ФРОНТАЛЬНАЯ ЛАБОРАТОРНАЯ РАБОТА 1. Определение цены деления измерительного прибора. ПРАКТИКУМ определения цены деления и погрешности измерений приборов.

Первоначальные сведения о строении вещества (11 ч.) Гипотеза о дискретном строении вещества. Молекулы. Непрерывность и хаотичность движения частиц вещества. Диффузия. Броуновское движение. Модели газа, жидкости и твердого тела. Взаимодействие частиц вещества. Взаимное притяжение и отталкивание молекул. Три состояния вещества.

Учебные понятия. Молекула, молекулярно-кинетическая теория, атом, ион, диффузия, осмос, броуновское движение, броуновская частица, термометр, абсолютный нуль температуры, шкала температур, шкала Кельвина, агрегатное состояние вещества, газ, жидкость, твёрдое тело, капилляры, капиллярность, кристалл, кристаллическое тело, аморфное тело.

Персоналии. Демокрит, М.В. Ломоносов, П. Гассенди, Р. Броун, А. Цельсий, У. Кельвин.

Демонстрации. 1. Диффузия в жидкостях и газах. 2. Модель броуновского движения. 3. Модель хаотического движения молекул в газе. 4. Зависимость скорости диффузии от температуры жидкости. 5. Прилипание стеклянной пластинки к воде. 6. Сцепление свинцовых цилиндров. 7. Смачивание и несмачивание твёрдого тела жидкостью. 8. Подъём воды по капиллярным трубкам. 9. Образцы (коллекция) кристаллических тел. 10. Модели кристаллических решёток. 
Домашние экспериментальные задания и опыты. 1. Изучение зависимости скорости диффузии от температуры. 2. Наблюдение капиллярности. 3. Изготовление «кораблика». 4. Выращивание кристаллов поваренной соли. 5. Сравнение температур воды в двух стаканах.

Основные образовательные идеи. Увидеть невидимое человеческим глазом. «Умные» материалы.

ФРОНТАЛЬНАЯ ЛАБОРАТОРНАЯ РАБОТА 2. ИзмеренИе размеров малых тел. Исследование броуновского движения молекул. Мини проект «Расчёт толщины тел методом рядов». Исследование под микроскопом кристаллов соли и сахара. Зачет по теме «Первоначальные сведения о строении вещества»

Взаимодействия тел (31 ч.) Механическое движение. Равномерное и не равномерное движение. Скорость. Расчет пути и времени движения. Траектория. Прямолинейное движение. Взаимодействие тел. Инерция. Масса. Плотность. Измерение массы тела на весах. Расчет массы и объема по его плотности. Сила. Силы в природе: тяготения, тяжести, трения, упругости. Закон Гука. Вес тела. Связь между силой тяжести и массой тела. Динамометр. Сложение двух сил, направленных по одной прямой. Трение. Упругая деформация.

Решение экспериментальных задач: «Оценка средней скорости движения человека при ходьбе и при беге». Построение и чтение графиков равномерного прямолинейного движения. Решение задач повышенной сложности по темам: «Механическое движение», «Расчет массы и объема тела по его плотности». Экспериментальная работа «Исследование связи массы вещества с его объемом». Исследование баллистического движения с помощь пистолета. Мини проект Определение средней скорости своего движения.

ФРОНТАЛЬНЫЕ ЛАБОРАТОРНЫЕ РАБОТЫ 3. ОПределение скорости равномерного прямолинейного движения с использованием цифровых технологий. 4. Измерение массы тела на рычажных весах. 5. Измерение объема тела. 6. Определение плотности твердого тела. 7. Градуирование пружины и измерение сил динамометром. 8. Измерение силы трения с помощью динамометра. Контрольная работа № 1 «Движение и взаимодействие тел». Зачет по теме «Взаимодействие тел».

Учебные понятия. Механическое движение, тело отсчёта, относительность движения, траектория, прямолинейное движение, криволинейное движение, пройденный путь, материальная точка, время, 
векторная физическая величина, скорость, спидометр, равномерное движение, средняя скорость, график пути, график скорости, сила, деформация тела, гравитация, гравитационное взаимодействие, инерция, инертность, масса тела, весы, объём тела, плотность вещества, гравитационное поле, сила тяжести, сила всемирного тяготения, центр тяжести, точка приложения силы, модуль силы, направление действия силы, упругая деформация, пластичная деформация, сила упругости, вес тела, невесомость, удлинение пружины, закон Гука, жёсткость пружины, динамометр, равнодействующая сил, сила трения, сила трения скольжения, сила трения качения, сила трения покоя.

Персоналии. Г. Галилей, Х. Гюйгенс, Аристотель, И. Ньютон, Р. Гук.

Демонстрации. 1. Механическое движение. 2. Способы измерения длины и времени. 3. Равномерное прямолинейное движение. 4. Взаимодействие тел. 5. Изменение скорости тела как результат действия силы. 6. Деформация тела как результат действия силы. 7. Явление инерции. 8. Тела равного объёма. 9. Тела равной массы. 10. Деформация различных тел под действием силы. 11. Зависимость деформации линейки от модуля, точки приложения и направления приложенной силы. 12. Зависимость деформации пружины от приложенной силы. 13. Сложение сил. 14. Зависимость силы трения от силы давления и от рода трущихся поверхностей.

Домашние экспериментальные задания и опыты. 1. Измерение времени между ударами пульса. 2. Измерение скорости горения свечи. 3. Измерение скорости равномерного движения. 4. Наблюдение явления инерции. 5. Определение плотности вещества. 6. Нахождение центра тяжести плоского тела. 7. Определение массы и веса воздуха в комнате.

Основные образовательные идеи. Движение, как объект изучения механики. Основы механики в военном деле.

Давление твердых тел, жидкостей и газов (29 ч.) Давление. Опыт Торричелли. Барометр-анероид. Атмосферное давление на различных высотах. Закон Паскаля. Способы увеличения и уменьшения давления. Давление газа. Вес воздуха. Воздушная оболочка. Измерение атмосферного давления. Манометры. Поршневой жидкостный насос. Передача давления твердыми телами, жидкостями, газами. Действие жидкости и газа на погруженное в них тело. Расчет давления жидкости на дно и стенки сосуда. Сообщающие сосуды. Архимедова сила. Гидравлический пресс. Плавание тел. Плавание судов. Воздухоплавание. 
Решение задач повышенной сложности на тему: «Давление твердого тела. Способы уменьшения и увеличения давления», «Расчет давления жидкости на дно и стенки сосуда», «Гидравлические машины, гидравлический пресс». Решение экспериментальных задач: «Оценка давления, оказываемого человеком на пол при ходьбе и в стоячем положении», «Оценка силы давления, оказываемого атмосферой на человека», «Оценка ватерлинии современных военных кораблей. Расчет водоизмещения подводных лодок», «Моделирование экологически безопасного шлюза».

ФРОНТАЛЬНЫЕ ЛАБОРАТОРНЫЕ РАБОТЫ 9. ОПределение выталкивающей силы, действующей на погруженное в жидкость тело. 10. Выяснение условий плавания тела в жидкости.

Контрольная работа № 2 по теме: «Давление твердых тел, жидкостей и газов». Контрольная работа № 3 по теме: «Архимедова сила». Зачет по теме: «Давление, гидростатика и аэростатика».

Учебные понятия. Сила давления, давление, площадь поверхности, гидростатическое давление, батисфера, батискаф, сообщающиеся сосуды, манометр, гидравлическая машина, гидравлический пресс, гидравлический тормоз, архимедова сила, закон Архимеда, гидростатическое взвешивание, ватерлиния, водоизмещение судна, подъёмная сила, атмосфера, атмосферное давление, ртутный барометр, барометр-анероид.

Персоналии. Б. Паскаль, О. Пиккар, Архимед, Гиерон, Ж.М. Монгольфье, Ж.Э. Монгольфье, Э. Торричелли.

Демонстрации. 1. Зависимость результата действия силы от площади опоры. 2. Давление жидкости на дно и стенки сосуда. 3. Увеличение давления жидкости с глубиной. 4. Манометр. 5. Сообщающиеся сосуды. 6. Зависимость давления газа от его температуры. 7. Зависимость давления газа от его объёма. 8. Опыт с шаром Паскаля. 9. Гидравлический пресс. 10. Действие выталкивающей силы. 11. Опыт с ведёрком Архимеда. 12. Плавание тел. 13. Взвешивание воздуха. 14. Опыт с магдебургскими полушариями. 15. Подъём жидкости за поршнем. 16. Барометр-анероид. 17. Поршневой насос.

Основные образовательные идеи. От инертной массы тела к весу тела, распределение давления твердого тела. Объяснение передачи давления сыпучих веществ (песка), сравнение с текучими явлениями воды. Давление газа на стенки сосуда согласно положениям МКТ. 
Работа. Мощность. Энергия (18 ч.) Работа. Мощность. Энергия. Кинетическая энергия. Потенциальная энергия. Закон сохранения механической энергии. Простые механизмы. КПД механизмов.

Рычаг. Равновесие сил на рычаге. Момент силы. Рычаги в технике, быту и природе. Применение закона равновесия рычага к блоку. Равенство работ при использовании простых механизмов. «Золотое правило» механики. Центр тяжести тела. Условие равновесия тел.

Решение задач повышенной сложности на тему: «Механическая работа. Мощность», «Определение КПД простых механизмов», «Превращение одного вида энергии в другой. Закон сохранения механической энергии».

ФРОНТАЛЬНЫЕ ЛАБОРАТОРНЫЕ РАБОТЫ 11. ВЫясненИе условия равновесия рычага. 12. Определение КПД при подъеме тела по наклонной плоскости.

Мини проект «Моделирование бумеранга». Контрольная работа № 4 «Работа. Мощность. Энергия»

Учебные понятия. Механическая работа, мощность, энергия, потенциальная энергия, кинетическая энергия, замкнутая система, полная механическая энергия, закон сохранения механической энергии, рычаг, плечо силы, момент силы, условие равновесия рычага, простые механизмы, неподвижный блок, подвижный блок, «золотое правило» механики, наклонная плоскость, полезная работа, полная работа, КПД механизма.

Персоналии. Д. Джоуль, Дж. Уатт, Архимед.

Демонстрации. 1. Переход потенциальной энергии тела в кинетическую энергию. (Движение тележки под действием опускающегося груза. Скатывание тела с наклонной плоскости.) 2. Рычаги. Равновесие рычага. 3. Подвижный и неподвижный блоки. 4. Опускание чашки весов при продувании под ней воздуха. 5. Пульверизатор. 6. Водоструйный насос.

Домашние экспериментальные задания и опыты. 1. Вычисление работы, совершаемой учеником при подъёме по лестнице. 2. Определение мощности, развиваемой учеником при подъёме на один этаж.

Основные образовательные идеи. Закон сохранения энергии фундаментальный закон природы. Изобретения человека от простых механизмов до машин, их область применения вчера, сегодня, завтра.

Повторение материала 7 класса (6ч.) Решение диагностических работ по темам физики 7 класса [9]. Квест-игра «Искатели клада». Мини проект «Физика в игрушках». 
Основные образовательные идеи. Диагностика достижения предметных и метапредметных результатов. Определение и развитие индивидуальной траектории ученика с помощью листа достижений учащегося [1].

«Мы много знаем, но мало что понимаем!» - эти слова А. Эйнштейна можно назвать лозунгом информационного XXI века. «Главное в мастерстве учителя - пробуждать радость познания и творчества» [10]. Содержание программы, основанного на принципе метапредметности позволяет учителю развивать научное мышление учащихся на основе межпредметных связей физики, воспитывать самостоятельность в обучении.

\section{Список литературы}

1. Боженкова Л.И. [Электронный ресурс] Методика формирования универсальных учебных действий при обучении алгебре // [Электронный pecypc]. Код доступа http://avidreaders.ru/download/metodika-formirovaniyauniversalnyh-uchebnyh-deystviy-pri-1.html?f=pdf.

2. Государственная программа Российской Федерации «Развитие образования» (утв. Постановлением Правительства РФ от 26.12.2017 № 1642 (ред. от 22.02.2021) «Об утверждении государственной программы Российской Федерации «Развитие образования». - http://www.consultant.ru/ document/cons_doc_LAW_286474/cf742885e783e08d9387d7364e34f26f87ec138f / (дата обращения: 10.03.2021).

3. Ивашкина Д.А. Эксперимент как метапредметная деятельность: реализация ФГОС на примере курса физики: курс лекций УМП - М.: Педагогический университет "Первое сентября" 2014. - 250 с.

4. Паспорт национального проекта «Образование» (утв. президиумом Совета при Президенте РФ по стратегическому развитию и национальным проектам, протокол от 24.12.2018 № 16). — URL: http://www.consultant.ru/ document/cons_doc_LAW_319308/ (дата обращения: 10.03.2021).

5. Снигирева Л.Н. Формирование познавательных универсальных учебных действий при установлении межпредметных связей математики и физики в условиях реализации образовательной программы среднего общего образования : монография / Л.Н. Снигирева. - Чебоксары: ИД «Среда», 2020. - 104 c. https://elibrary.ru/item.asp?id=43941594. 
6. Федеральный закон от 29.12.2012 № 273-Ф3 (ред. от 31.07.2020) «Об образовании в Российской Федерации» (с изм. и доп., вступ. в силу с 01.09.2020).-URL:http://www.consultant.ru/document/cons_doc_LAW_140174 (дата обращения: 28.09.2020).

7. Хуторской А.В. Метапредметное содержание и результаты образования: как реализовать федеральные государственные образовательные стандарты (ФГОС) // [Электронный ресурс]. Код доступа http://www.eidos.ru/journal/2012/0229-10.htm.

8. Хуторской А.В. Работа с метапредметным компонентом нового образовательного стандарта. Практический аспект // Народное образование. 2013. - № 4. C. 159-160.

9. Шахматова В.В. Физика: Диагностические работы к учебнику А.В. Перышкина: Учебно-методическое пособие - М: Дрофа 2015, 124 с.

10. Thomas Friedman, Learning to Keep Learning // New York Times. 13.12.2006.

\section{ЗАИМСТВОВАНИЯ}

$22,9 \%$

\section{САМОЦИТИРОВАНИЯ}

$0 \%$

\section{ЦИТИРОВАНИЯ}

$0 \%$

ОРИГИНАЛЬНОСТЬ

$77,1 \%$

источников: 3

\section{ТЕКСТОВЫЕ МЕТРИКИ}

\section{СЕМАНТИЧЕСКИЕ ХАРАКТЕРИСТИКИ}

Рубрикатор ВАК документа >

Рубрикатор ГРНТИ документа >

Рубрикатор УдК документа >

Оценка связности текста: 75.8064516129032 >

Наличие описания результатов исследования: да >

Наличие описания метода исследования: да >

Наличие введения: нет >

Наличие выводов: нет >

Наличие библиографии: да >

Наличие аннотации: да >

Доля общей лексики: 0 >

Доля научной лексики: 100 > 